OPEN ACCESS

Edited by:

Scott Douglas Newsome, Johns Hopkins Medicine,

United States

Reviewed by:

Mariano Marrodan

Fundación Para la Lucha Contra las Enfermedades Neurológicas de la Infancia (FLENI), Argentina Bastien Joubert,

Hospices Civils de Lyon, France

*Correspondence: Yuping Wang mdwangyp@sina.cn

Specialty section: This article was submitted to Multiple Sclerosis and Neuroimmunology, a section of the journal

Frontiers in Immunology

Received: 12 November 2021 Accepted: 01 February 2022

Published: 17 February 2022

Citation:

Jia Y, Li M, Li D, Zhang $M$, Wang $H$, Jiao L, Huang Z, Ye J, Liu A and Wang Y (2022) Immune-Mediated Cerebellar Ataxia Associated With Neuronal Surface Antibodies.

Front. Immunol. 13:813926. doi: 10.3389/fimmu.2022.813926

\section{Immune-Mediated Cerebellar Ataxia Associated With Neuronal Surface Antibodies}

\author{
Yu Jia ${ }^{1}$, Mingyu $L i^{1}$, Dawei $L i^{1}$, Mengyao Zhang ${ }^{1}$, Huifang Wang ${ }^{1}$, Lidong Jiao ${ }^{1}$, \\ Zhaoyang Huang ${ }^{1,2,3,4}$, Jing Ye ${ }^{1,2,3}$, Aihua Liu ${ }^{1,2,3}$ and Yuping Wang ${ }^{1,2,3,4^{*}}$ \\ ${ }^{1}$ Department of Neurology, Xuanwu Hospital, Capital Medical University, Beijing, China, ${ }^{2}$ Beijing Key Laboratory of \\ Neuromodulation, Capital Medical University, Beijing, China, ${ }^{3}$ Center of Epilepsy, Beijing Institute for Brain Disorders, Capital \\ Medical University, Ministry of Science and Technology, Beijing, China, ${ }^{4}$ Institute of Sleep and Consciousness Disorders, \\ Beijing Institute of Brain Disorders, Collaborative Innovation Center for Brain Disorders, Capital Medical University, Beijing, China
}

Background: Immune-mediated cerebellar ataxias (IMCAs) are common in paraneoplastic cerebellar degeneration (PCD) but rarely occur in patients with neuronal surface antibodies (NSAbs). Although cerebellar ataxias (CAs) associated with antiNMDAR and anti-CASPR2 have been reported in a few cases, they have never been studied systematically. This study aimed to analyze the characteristics of anti-NSAbsassociated CAs.

Methods: A retrospective investigation was conducted to identify patients using the keywords IMCAs and NSAbs. We collected the clinical data of 14 patients diagnosed with anti-NSAbs-associated CAs.

Results: The median age was 33 years (16-66), and the male-to-female ratio was 4:3. Nine were positive for NMDAR-Ab, two for LGl1-Ab, two for CASPR2-Ab, and one for AMPA2R-Ab. CAs were initial symptoms in three patients and presented during the first two months of the disease course (10 days on average) among the rest of the patients. After the immunotherapy, two cases were free from symptoms, and eight cases recovered satisfactorily (10/14, 71.4\%). Compared with other causes of IMCAs, antiNSAbs were more frequently associated with additional extra-cerebellar symptoms (85.7\%), mostly seizures (78.6\%) and mental abnormalities (64.3\%). In the CSF analysis, pleocytosis was detected in ten patients (71.4\%) and oligoclonal bands (OB) were observed in nine patients (64.3\%). Moreover, compared with PCD and anti-GAD65-Ab-associated CAs, anti-NSAbs-associated CAs showed a better response to immunotherapy.

Conclusion: IMCAs are rare and atypical in autoimmune encephalitis with neuronal surface antibodies. Compared with other forms of IMCAs, more symptoms of encephalopathy, a higher rate of pleocytosis and positive OB in CSF, and positive therapeutic effect were the key features of anti-NSAbs-associated CAs.

Keywords: immune-mediated cerebellar ataxia, neuronal surface antibodies, CSF analysis, oligoclonal bands, immunotherapy 


\section{INTRODUCTION}

Over the past few decades, with the discovery of anti-NMDAR encephalitis in 2007 (1), an increasing number of specific neuronal surface antibodies (NSAbs) have been discovered, including LGI1-Ab, CASPR2-Ab, AMPA1/2R-Ab, GABAR-A/ $\mathrm{B}-\mathrm{Ab}$, and so on (2-5). Anti-NSAbs-associated autoimmune encephalitis presents diverse clinical phenotypes, such as seizures, cognitive decline, psychiatric abnormalities, and autonomic dysfunction. In contrast, symptoms of cerebellar ataxia are reported rarely in patients with positive NSAbs (6-8).

Immune-mediated cerebellar ataxias (IMCAs) are one of the most common symptoms of paraneoplastic cerebellar degeneration (PCD) (9). Previous studies have suggested that CAs are atypical in anti-NSAbs-associated autoimmune encephalitis $(6,7,10)$. For example, cerebellar ataxia has been reported in a few patients with anti-NMDAR encephalitis $(10,11)$. Boyko et al. found that about 15\% of patients with anti-CASPR2 encephalitis developed cerebellar ataxia followed by the onset of limbic symptoms or Morvan syndrome (12). Although CAs associated with anti-NMDAR and anti-CASPR2 have been studied in a few cases, they have not been studied systematically. In this study, we summarized the clinical features of 14 patients with anti-NSAbs-associated CAs. Moreover, to explore the distinct features of anti-NSAbs-associated CAs, a study of two overlapping cohorts, including patients diagnosed as IMCAs and patients with NSAbs from 2015 to 2020 in our center, was designed and conducted. The present study focused on the clinical characteristics of patients with anti-NSAbs-associated CAs.

\section{METHODS}

\section{Patient Identification}

A retrospective investigation was conducted on outpatient and hospitalized cases in the Department of Neurology, Xuanwu Hospital, Capital Medical University from June 2015 to June 2020 to identify potential patients with anti-NSAbs-associated CAs using the keywords NSAbs and IMCAs. 54 patients with IMCAs and 191 patients positive for NSAbs were enrolled.

All 54 patients were screened for common causes of IMCAs, including PCD, anti-GAD65-Ab-associated CA, post-infectious cerebellitis, gluten ataxia (GA), opsoclonus myoclonus syndrome (OMS), Miller Fisher syndrome, Hashimoto's encephalopathy (HE) and Systemic Lupus Erythematosus (SLE). Among 54 patients, 13 patients were diagnosed with PCDs (7 with Yo-Ab, 3 with $\mathrm{Hu}-\mathrm{Ab} 2$ with $\mathrm{Tr}-\mathrm{Ab}$, and 1 with SOX1-Ab), 7 patients with anti-GAD65-Ab-associated CA, 6 with autoimmune disease-associated CAs (4 with Hashimoto's Encephalopathy and 2 with Systemic Lupus Erythematosus), 14 with unknown etiology and the remaining 14 patients were positive for NSAbs,

\footnotetext{
Abbreviations: NSAbs, Neuronal surface antibodies; PCD, Paraneoplastic cerebellar degeneration; ONAs, Onconeural antibodies; MRI, Magnetic resonance imaging; mRS, Modified Rankin score; WBC, White blood cell counts; OB, Oligoclonal bands; IMCAs, Immune-mediated cerebellar ataxias; GA, Gluten ataxia; OMS, Opsoclonus myoclonus syndrome.
}

including 9 with NMDAR-Ab, 2 with LGI1-Ab, 2 with CASPR2$\mathrm{Ab}$ and 1 with AMPA2R-Ab. Figure 1 demonstrates the process of identifying patients in this study. These 14 patients were negative for onconeural antibodies (ONAs), anti-GAD-65 antibodies, GQ1b antibodies, anti-gliadin antibodies (AGA), anti-thyroid antibodies (ATA), anti-nuclear antibody (ANA), and anti-double-stranded DNA antibodies. In addition, there was no history of virus infection, dermatitis herpetiformis (DH), and celiac disease $(\mathrm{CD})$ in all. Moreover, routine screening examinations, including muti-tumor markers and whole-body PET-CT, showed no malignant tumors in these 14 cases. Alternative causes of cerebellar autoimmunity, such as Gluten Ataxia, PCD, anti-GAD65-Ab-associated CA, and autoimmune disease-associated CA, were excluded.

Patients with PCD, anti-GAD65-Ab-associated CA, and autoimmune disease-associated CAs were included as the control groups to explore the clinical characteristics of IMCAs associated with these antibodies. Then we reviewed the clinical information of the remaining 177 patients with antibodies targeting NSAbs, and all patients met the diagnostic criteria for autoimmune encephalitis (13). We compared the clinical characteristics of patients with or without CAs to identify the occurrence rate of IMCAs in autoimmune encephalitis.

\section{Antibody Detection}

All patients were screened for immunoglobulin G (IgG) against common antigens of autoimmune encephalopathy antibodies using indirect immunofluorescence assays (IFAs) (EUROIMMUN, FA112d-1, Germany) and the cell-based assays Euroimmun kit (commercial CBA) prior to the treatments, including antibodies targeting NMDAR, LGI1, CASPR2, AMPA1/2-R, GABA-A/B-R, DPPX, IgLON5, MOG, and onconeural antibodies (ONAs), including $\mathrm{Hu}-\mathrm{Ab}$, Yo- $\mathrm{Ab}, \mathrm{Ri}-\mathrm{Ab}$, CV2-Ab, PNMA2 (Ma-2/Ta) -Ab, Amphiphysin-Ab, SOX1-Ab, $\operatorname{Tr}-\mathrm{Ab}$, and GAD65-Ab. As previously reported (4-6), tissuebased assays (TBAs) using rat brain tissue and CBAs using human embryonic kidney 293 (HEK293) cells were utilized for antibodies detection.

The initial dilution titers of serum and CSF were 1:10 and 1:1, respectively. Antibody titers were defined as three levels. For the antibody titers in serum, 1:10, 1:32 to 1:100, and 1:320 or above were defined as weakly positive, positive, and strongly positive, respectively. In CSF, 1:1, 1:3.2 to 1:10, and 1:32 or above were defined as weakly positive, positive, and strongly positive (14).

\section{Clinical Data and Outcome Measures}

Detailed clinical information including demographic, clinical manifestation, CSF analysis, and brain magnetic resonance imaging (MRI) of all patients was collected. The symptoms of cerebellar ataxia were recorded as gait ataxia, slurred speech, limb dysmetria, and nystagmus. All patients received immunotherapy after diagnosis. Glucocorticoids, intravenous immunoglobulin (IVIG), and plasma exchange were classified as first-line therapy with other immunosuppressants as second-line therapy. The therapeutic regimen and responsiveness to immunotherapy of patients were collected, and the outcome was evaluated by modified Rankin score (mRS) after discharge with a reduction 


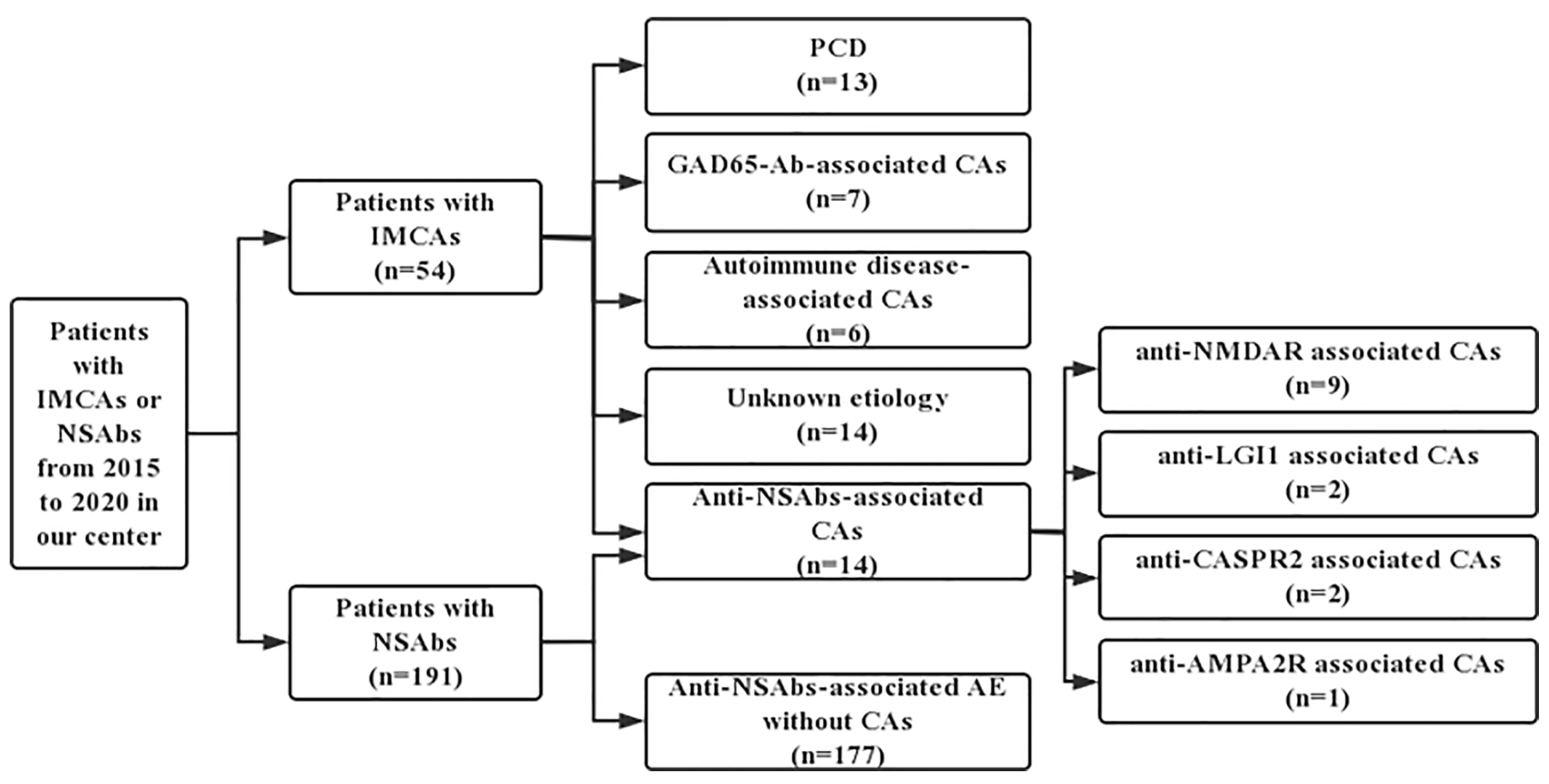

FIGURE 1 | The process of identifying patients from IMCAs and anti-NSAbs cohorts. NSAbs, Neuronal surface antibodies; NSAbs, Neuronal surface antibodies; PCD, Paraneoplastic cerebellar degeneration; AE, autoimmune encephalitis.

of $\mathrm{mRS} \geq 1$ during follow-ups defined as efficacious. Relapse of encephalitis was defined as the new onset or worsening of symptoms occurring after at least 2 months of improvement or stabilization (10).

\section{Statistical Analysis}

Statistical analysis was performed with IBM SPSS V.23.0. Summary statistics were reported as median (range, minimum-maximum) for continuous variables, frequencies, and percentages for categorical variables. As appropriate, clinical data were compared using Pearson's $\chi 2$, Fisher's exact test, or Mann-Whitney U test. $\mathrm{P}<0.05$ was considered statistically significant.

\section{RESULTS}

\section{Frequency of Anti-NSAbs-Associated CAs}

Among the 40 IMCAs with definite etiology, 14 patients (25.9\%) were identified as anti-NSAbs associated CAs, followed by PCD (13 patients, $24.1 \%$ ), anti-GAD65-Ab-associated CAs (7 patients, $13.0 \%$ ), and autoimmune disease-associated CAs (6 patients, 11.1\%) (Table 1). Regarding the 191 patients with positive NSAbs (adult, 164; children, 27), 14 patients (7.3\%) developed CAs during the disease period. The result showed a similar proportion of cerebellar ataxia, respectively, in adults (12/164, $7.3 \%)$ and children $(2 / 27,7.4 \%)(\mathrm{P}=1.000)$ (Table 2). Compared with other causes of IMCAs or anti-NSAbs without CAs, no distinct features in demographic data were found in patients with Anti-NSAbs-associated CAs
According to the data, 185 patients were positive with one antibody (108 with NMDAR-Ab, 52 with LGI1-Ab, 12 with CASPR2-Ab, 4 with AMPA2R-Ab, and 9 with GABAR-B-Ab), and 6 patients were positive with two types of antibodies (4 with NMDAR-Ab and CASPR2-Ab, and 2 with CASPR2-Ab and LGI1-Ab) (Table 3). Figures suggested that patients with AMPAR-Ab had the highest occurrence of cerebellar ataxia during the course of the disease $(1 / 4,25 \%)$, followed by CASPR2-Ab (2/12, 16.7\%), NMDAR-Ab (9/108, 8.3\%), and LGI1-Ab (2/52, 3.8\%). However, the symptoms of CAs were not apparent among patients with GABAB-R-Ab (0/9, 0\%). Moreover, the occurrence of multiple antibodies was not related to the increased frequency of CAs $(0 / 6,0 \%)$.

\section{Clinical Characteristics of Patients With CAs}

Regarding 14 patients with CAs, three patients suffered from gait ataxia as the initial symptom (two with NMDAR-Ab and one with CASPR2-Ab). The other 11 patients experienced cerebellar ataxia during the first two months after the disease onset (2-60 days, average on day 10). CAs installed acutely (10 patients, $71.4 \%$ ), subacutely (1 patient, $7.1 \%$ ) and insidiously (3 patients, 21.4\%). Cerebellar signs are shown in Table 1. Most patients presented with slurred speech as a main symptom $(78.6 \%)$, but nystagmus seldom appeared (35.7\%). In addition, two patients (one with NMDAR-Ab and the other with CASPR2-Ab) had isolated CAs throughout the disease (Table 4). The neurological examination revealed that five patients (35.7\%) failed to complete the alternating movement test with both two hands, 
TABLE 1 | Comparison of clinical features of four forms of IMCAs.

\begin{tabular}{|c|c|c|c|c|c|}
\hline Variables (n,\%) & $\begin{array}{l}\text { Anti-NSAbs-associated CAs } \\
\qquad(n=14)\end{array}$ & $\begin{array}{c}\text { PCD } \\
(n=13)\end{array}$ & $\begin{array}{l}\text { Anti-GAD65-Ab-associated CAs } \\
\qquad(\mathrm{n}=7)\end{array}$ & $\begin{array}{l}\text { Autoimmune disease-associated CAs } \\
\qquad(n=6)\end{array}$ & $\mathbf{P}$ \\
\hline Male(\%) & $8(57.1 \%)$ & 7 (53.8\%) & $1(14.3 \%)$ & $2(33.3 \%)$ & 0.268 \\
\hline Age(year) & $33(16-66)$ & $56(37-66)$ & $39(23-68)$ & $40.5(21-56)$ & 0.363 \\
\hline \multicolumn{6}{|l|}{ Cerebellar signs } \\
\hline Gait ataxia & 7 (50\%) & 13(100\%) & $6(85.7 \%)$ & 5(83.3\%) & 0.010 \\
\hline Limb dysmetria & 5 (35.7\%) & $11(84.6 \%)$ & $5(71.4 \%)$ & $4(66.6 \%)$ & 0.064 \\
\hline Slurred speech & $11(78.6 \%)$ & $7(53.8 \%)$ & $3(42.9 \%)$ & $4(75.0 \%)$ & 0.361 \\
\hline Nystagmus & $5(35.7 \%)$ & $6(46.2 \%)$ & $4(57.1 \%)$ & $2(33.3 \%)$ & 0.797 \\
\hline \multicolumn{6}{|l|}{ CAs symptoms } \\
\hline As the initial symptom & 3 (21.4\%) & 12(92.3\%) & $3(42.9 \%)$ & $1(16.7 \%)$ & $<0.01$ \\
\hline As the only symptom & $2(14.3 \%)$ & $8(61.5 \%)$ & $2(28.6 \%)$ & $1(16.7 \%)$ & 0.057 \\
\hline \multicolumn{6}{|l|}{ Other symptoms } \\
\hline Seizure onset & $11(78.6 \%)$ & 0 & $3(42.9 \%)$ & $2(33.3 \%)$ & $<0.01$ \\
\hline Memory loss & 9 (64.3\%) & $2(15.4 \%)$ & $4(57.1 \%)$ & $5(83.3 \%)$ & 0.017 \\
\hline Mental abnormalities & 9 (64.3\%) & $2(15.4 \%)$ & $1(14.3 \%)$ & $4(66.6 \%)$ & 0.015 \\
\hline \multicolumn{6}{|l|}{ CSF analysis } \\
\hline Pleocytosis & $10(71.4 \%)$ & $1(7.7 \%)$ & $2(28.6 \%)$ & $1(16.7 \%)$ & $<0.01$ \\
\hline Elevated protein & $4(28.6 \%)$ & $3(23.1 \%)$ & $2(28.6 \%)$ & $2(33.3 \%)$ & 1.000 \\
\hline Positive OB & 9 (64.3\%) & $1(7.7 \%)$ & 0 & 0 & $<0.01$ \\
\hline Cerebellar atrophy on MRI & $1(7.1 \%)$ & $4(30.8 \%)$ & $3(42.9 \%)$ & $2(33.3 \%)$ & 0.206 \\
\hline \multicolumn{6}{|l|}{ Outcomes } \\
\hline Good & $7(50 \%)$ & 0 & $1(14.3 \%)$ & $2(33.3 \%)$ & 0.011 \\
\hline Mild & $3(21.4 \%)$ & $2(15.4 \%)$ & $2(28.6 \%)$ & $3(50 \%)$ & 0.454 \\
\hline Poor & $4(28.6 \%)$ & $11(84.6 \%)$ & $4(57.1 \%)$ & $1(16.7 \%)$ & $<0.01$ \\
\hline
\end{tabular}

IMCAs, Immune-mediated cerebellar ataxias; NSAbs, Neuronal surface antibodies; PCD, Paraneoplastic cerebellar degeneration; CAs, Cerebellar ataxias; OB, Oligoclonal bands; CSF, Cerebrospinal fluid; MRl, Magnetic resonance imaging.

TABLE 2 | Comparison of clinical characteristic of patients positive for NASbs with and without CAs.

\begin{tabular}{|c|c|c|c|}
\hline Variables (n,\%) & With CAs $(n=14)$ & Without CAs $(n=177$ ) & $\mathbf{P}$ \\
\hline Male(\%) & $8(57.1 \%)$ & $102(57.6 \%)$ & 1.000 \\
\hline Age(year) & $33(16-66)$ & $24(6-72)$ & 0.419 \\
\hline \multicolumn{4}{|l|}{ Initial symptoms } \\
\hline Seizure onset & $3(21.4 \%)$ & $73(41.2 \%)$ & 0.168 \\
\hline Memory loss & $2(14.3 \%)$ & $24(13.6 \%)$ & 1.000 \\
\hline Mental abnormalities & $3(21.4 \%)$ & $54(30.5 \%)$ & 0.681 \\
\hline \multicolumn{4}{|l|}{ Cerebrospinal fluid analysis } \\
\hline Pleocytosis & $10(71.4 \%)$ & $95(53.7 \%)$ & 0.268 \\
\hline Elevated protein & $4(28.6 \%)$ & $86(48.6 \%)$ & 0.174 \\
\hline Elevated lgG & $2(14.3 \%)$ & $71(40.1 \%)$ & 0.084 \\
\hline Positive OB & $9(64.3 \%)$ & $55(31.1 \%)$ & 0.025 \\
\hline \multicolumn{4}{|l|}{ Antibodies detection } \\
\hline Positive $A b$ in serum & $9(64.3 \%)$ & 168 (94.9\%) & $<0.01$ \\
\hline Positive Ab in CSF & 13 (92.9\%) & $142(80.2 \%)$ & 0.419 \\
\hline Signs of encephalitis on brain MRI* & 7 (50\%) & $70(39.5 \%)$ & 0.573 \\
\hline \multicolumn{4}{|l|}{ Outcomes } \\
\hline Good & 7 (50\%) & 92 (52.0\%) & 1.000 \\
\hline Mild & 3 (21.4\%) & 39 (22.0\%) & 1.000 \\
\hline Poor & 4 (28.6\%) & 46 (26.0\%) & 1.000 \\
\hline
\end{tabular}

NSAbs, Neuronal surface antibodies; CAs, Cerebellar ataxias; OB, Oligoclonal bands; CSF, Cerebrospinal fluid; Ab, Antibody; MRl, Magnetic resonance imaging

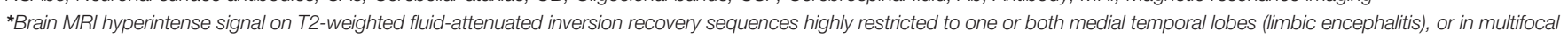
areas involving grey matter, white matter (13).

TABLE 3 | The data of antibodies detection in patients with anti-NSAbs.

\begin{tabular}{|c|c|c|c|c|c|c|}
\hline Antibodies detection & NMDAR (n = 108) & LGI1 ( $n=52)$ & CASPR2 $(n=12)$ & GABAR $(n=9)$ & AMPAR $(n=4)$ & Two antibodies $(n=6)$ \\
\hline In serum (\%) & 8 (7.4\%) & 18 (34.6\%) & 6 (50.0\%) & 3 (33.3\%) & 1 (25.0\%) & 0 \\
\hline In CSF (\%) & $9(8.3 \%)$ & $1(1.9 \%)$ & $1(8.3 \%)$ & 0 & 1 (25.0\%) & 2 (33.3\%) \\
\hline Both serum and CSF (\%) & $91(84.3 \%)$ & $33(63.5 \%)$ & $5(41.7 \%)$ & $6(66.7 \%)$ & $2(50.0 \%)$ & $4(66.7 \%)$ \\
\hline
\end{tabular}

NSAbs, Neuronal surface antibodies; CSF, Cerebrospinal fluid. 
TABLE 4 | Clinical characteristics of patients with anti-NSAbs-associated CAs.

\begin{tabular}{|c|c|c|c|c|c|c|c|c|c|c|c|c|c|c|c|c|c|c|}
\hline \multirow[t]{2}{*}{ Case } & \multirow[t]{2}{*}{ Gender } & \multirow[t]{2}{*}{ Age } & \multirow[t]{2}{*}{ Antibody } & \multirow{2}{*}{$\begin{array}{l}\text { Initial } \\
\text { symptom }\end{array}$} & \multicolumn{3}{|c|}{ Cerebellar ataxia } & \multirow{2}{*}{$\begin{array}{l}\text { Accompanying } \\
\text { symptoms }\end{array}$} & \multicolumn{4}{|c|}{ CSF } & \multicolumn{2}{|c|}{ MRI } & \multirow[t]{2}{*}{ Tumor } & \multirow[t]{2}{*}{ Immunotherapy } & \multirow{2}{*}{$\begin{array}{l}\text { Follow- } \\
\text { up time } \\
\text { (months) }\end{array}$} & \multirow{2}{*}{$\begin{array}{l}\text { Therapeutic } \\
\text { effect of } \\
\text { cerebellar } \\
\text { ataxia }\end{array}$} \\
\hline & & & & & $\begin{array}{l}\text { Onset } \\
\text { type }\end{array}$ & $\begin{array}{l}\text { Onset } \\
\text { time } \\
\text { (day) }\end{array}$ & Manifestations & & WBC & Protein & $\lg G$ & OB & $\begin{array}{c}\text { Cerebellar } \\
\text { hyperintensity }\end{array}$ & $\begin{array}{l}\text { Cerebellar } \\
\text { atrophy }\end{array}$ & & & & \\
\hline 1 & M & 55 & AMPAR & $\begin{array}{l}\text { memory } \\
\text { decline }\end{array}$ & acute & 4 & $\begin{array}{l}\text { gait ataxia, } \\
\text { slurred speech }\end{array}$ & $\begin{array}{l}\text { seizure onset, } \\
\text { mental } \\
\text { abnormalities, } \\
\text { autonomic } \\
\text { dysfunction }\end{array}$ & 33 & 18 & 3.51 & Pos & Yes & No & No & $\begin{array}{l}\text { Steroids, IVIG, } \\
\text { plasma exchange } \\
\text { and } \\
\text { immunosuppressant }\end{array}$ & 24 & Poor \\
\hline 2 & $\mathrm{~F}$ & 40 & CASPR2 & $\begin{array}{l}\text { limbs } \\
\text { numbness }\end{array}$ & subacute & 15 & $\begin{array}{l}\text { gait ataxia, } \\
\text { slurred speech }\end{array}$ & $\begin{array}{l}\text { neuropathic } \\
\text { pain, muscle } \\
\text { cramps, } \\
\text { autonomic } \\
\text { dysfunction }\end{array}$ & 6 & 40 & 4.76 & Pos & Yes & No & No & Steroids & 15 & poor \\
\hline 3 & M & 35 & CASPR2 & $\begin{array}{l}\text { cerebellar } \\
\text { ataxia }\end{array}$ & acute & 1 & $\begin{array}{l}\text { gait ataxia, } \\
\text { nystagmus }\end{array}$ & No & 0 & 38 & 2.19 & Neg & No & Yes & No & Steroids & 24 & Full recovery \\
\hline 4 & $M$ & 64 & LGl1 & $\begin{array}{l}\text { seizure } \\
\text { onset }\end{array}$ & insidious & 30 & slurred speech & memory decline & 1 & 25 & 2.14 & Neg & No & No & No & Steroids & 42 & $\begin{array}{l}\text { Relieved } \\
\text { significantly }\end{array}$ \\
\hline 5 & M & 67 & LGl1 & confusion & acute & 10 & gait ataxia & $\begin{array}{l}\text { seizure onset, } \\
\text { mental } \\
\text { abnormalities, } \\
\text { autonomic } \\
\text { dysfunction }\end{array}$ & 1 & 51 & 3.93 & Neg & No & No & No & Steroids and IVIG & 40 & $\begin{array}{l}\text { Relieved } \\
\text { mildly }\end{array}$ \\
\hline 6 & M & 43 & NMDAR & $\begin{array}{l}\text { mental } \\
\text { abnormalities }\end{array}$ & insidious & 30 & $\begin{array}{l}\text { gait ataxia, } \\
\text { slurred } \\
\text { speech, } \\
\text { nystagmus }\end{array}$ & $\begin{array}{l}\text { seizure onset, } \\
\text { memory decline }\end{array}$ & 35 & 28 & 3.94 & Pos & No & No & No & Steroids and IVIG & 36 & Poor \\
\hline 7 & M & 66 & NMDAR & $\begin{array}{l}\text { mental } \\
\text { abnormalities }\end{array}$ & insidious & 60 & $\begin{array}{l}\text { gait ataxia, } \\
\text { slurred } \\
\text { speech,limb } \\
\text { dysmetria }\end{array}$ & $\begin{array}{l}\text { seizure onset, } \\
\text { memory decline }\end{array}$ & 15 & 33 & 3.87 & Pos & Yes & No & No & Steroids and IVIG & 30 & Poor \\
\hline 8 & M & 27 & NMDAR & $\begin{array}{l}\text { memory } \\
\text { decline }\end{array}$ & acute & 2 & $\begin{array}{l}\text { slurred } \\
\text { speech, } \\
\text { nystagmus }\end{array}$ & $\begin{array}{l}\text { seizure onset, } \\
\text { mental } \\
\text { abnormalities }\end{array}$ & 11 & 36 & 3.65 & Pos & No & No & No & Steroids & 15 & $\begin{array}{l}\text { Relieved } \\
\text { significantly }\end{array}$ \\
\hline 9 & $\mathrm{~F}$ & 16 & NMDAR & $\begin{array}{l}\text { mental } \\
\text { abnormalities }\end{array}$ & acute & 5 & $\begin{array}{l}\text { slurred } \\
\text { speech, limb } \\
\text { dysmetria }\end{array}$ & $\begin{array}{l}\text { seizure onset, } \\
\text { autonomic } \\
\text { dysfunction, } \\
\text { memory decline }\end{array}$ & 18 & 29 & 2.29 & Pos & No & No & No & Steroids & 16 & $\begin{array}{l}\text { Relieved } \\
\text { significantly }\end{array}$ \\
\hline 10 & F & 17 & NMDAR & $\begin{array}{l}\text { seizure } \\
\text { onset }\end{array}$ & acute & 10 & $\begin{array}{l}\text { slurred } \\
\text { speech, limb } \\
\text { dysmetria }\end{array}$ & $\begin{array}{l}\text { mental } \\
\text { abnormalities, } \\
\text { memory decline }\end{array}$ & 8 & 24 & 2.13 & Neg & No & No & No & Steroids & 48 & $\begin{array}{l}\text { Relieved } \\
\text { mildly }\end{array}$ \\
\hline 11 & $\mathrm{~F}$ & 27 & NMDAR & $\begin{array}{l}\text { cerebellar } \\
\text { ataxia }\end{array}$ & acute & 1 & $\begin{array}{l}\text { Nystagmus, } \\
\text { limb dysmetria }\end{array}$ & $\begin{array}{l}\text { seizure onset, } \\
\text { mental } \\
\text { abnormalities, } \\
\text { autonomic } \\
\text { dysfunction }\end{array}$ & 89 & 89 & 12.6 & Pos & No & No & No & Steroids & 27 & $\begin{array}{l}\text { Relieved } \\
\text { significantly }\end{array}$ \\
\hline
\end{tabular}




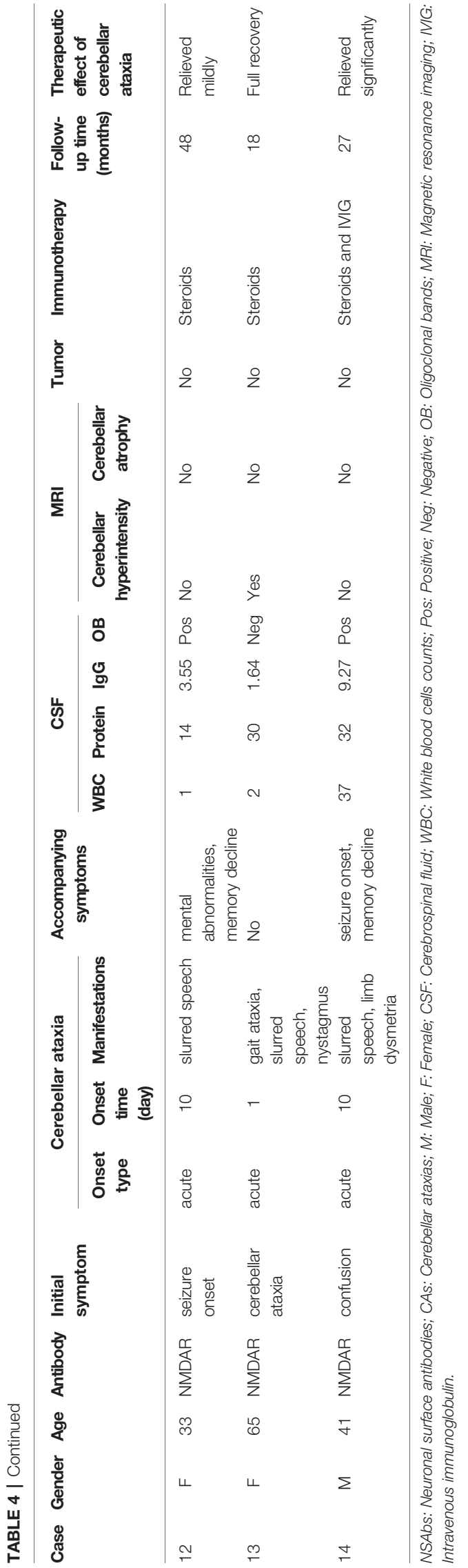

six patients $(42.9 \%)$ went through the finger-nose test with difficulties, and five patients (35.7\%) could not finish the heelknee-tibia test. However, there were not enough patients for clinical characteristics comparison among different antibodies.

\section{Laboratory Testing and MRI Analysis}

Blood and CSF markers indicating inflammation were evaluated. Among patients with NSAbs, oligoclonal bands (OB) in CSF were more frequently in patients with anti-NSAbs-associated CAs than in patients without CAs $(\mathrm{P}=0.025)$. The proportions of negative, weakly positive, positive and strongly positive NSAbs were further analyzed (Table 5). Interestingly, more patients with CAs were found to have high titer range of CSF antibodies (within "positive" group and "strongly positive" group, $85.7 \%$ vs 45.8\%, $\mathrm{P}=0.005)$. All 14 patients underwent 3T brain MRI. Cerebellar abnormalities on MRI are listed in Table 4. Limbic system involvement (medial temporal T2/FLAIR signal changes) (13) was found in seven patients (50\%). All 14 cases were negative for routine tumor screening.

\section{Response to the Immunotherapy}

All 14 patients were followed up for at least 15 months after discharge (median 27 months, ranging from 15-48 months). At the early stage, the patients were investigated by the standardized questionnaire through a telephone survey once a month, and all patients were hospitalized again for disease re-evaluation 6 months after discharge. Two patients were free from the symptoms of cerebellar ataxia, and eight recovered satisfactorily (10/14, 71.4\%) after the glucocorticoid treatment or the combination of glucocorticoids and IVIG (Table 4). In addition, two patients (patients 8 and 12) with NMDAR-Ab had clinical relapses, whereas the symptoms of cerebellar ataxia were not observed during the relapses. No malignancy was found in these 14 patients until the last follow-up visit. Follow-up brain MRI showed an obvious diminishment in cerebellar T2/FLAIR-hyperintense lesions in two patients $(2 / 4,50 \%$, case 7 and 13) and no significant changes in others (case 1 and case 2). However, cerebellar atrophy in brain MRI of case 3 remained unchanged.

\section{DISCUSSION}

IMCAs are a rare spectrum of diseases, and several specific neuronal antibodies were identified in IMCAs, such as the onconeural antibodies (Yo-Ab, Hu-Ab, CV2-Ab, Ri-Ab, and Ma-2-Ab) for PCDs, GAD65-Ab for anti-GAD65 Abassociated CA, and Ri-Ab for OMS (15-20). However, only a few studies have concentrated on the anti-NSAbs-associated CAs in autoimmune encephalitis (6-8). Research conducted by Iizuka $\mathrm{T}$ et al. revealed that approximately $5 \%$ of patients with antiNMDAR encephalitis showed cerebellar complaints during the disease course (11). Boyko et al. reviewed the clinical data of 163 patients with CASPR2-Ab and found that 24 patients $(14.7 \%)$ developed CAs (12). However, no large-sample clinical observation and follow-up studies have been conducted to explore the frequency of cerebellar ataxia in patients with antiAMPAR, anti-LGI1, or anti-GABABR encephalitis by far $(8,21)$. 
TABLE 5 | The levels of antibodies titers in patients with anti-NSAbs-associated CAs.

\begin{tabular}{|c|c|c|c|c|}
\hline \multirow[t]{2}{*}{ Range of antibody titers } & \multicolumn{2}{|c|}{ With cerebellar ataxia $(n=14)$} & \multicolumn{2}{|c|}{ Without cerebellar ataxia $(n=177)$} \\
\hline & Serum & CSF & Serum & CSF \\
\hline Negative & $5(35.7 \%)$ & $1(7.1 \%)$ & $9(5.1 \%)$ & $35(19.8 \%)$ \\
\hline Weakly positive & $1(7.1 \%)$ & $1(7.1 \%)$ & $54(30.5 \%)$ & $47(26.6 \%)$ \\
\hline Positive & $8(57.1 \%)$ & $7(50 \%)$ & $89(50.3 \%)$ & $50(28.2 \%)$ \\
\hline Strongly positive & 0 & $5(35.7 \%)$ & $11(6.2 \%)$ & $31(17.5 \%)$ \\
\hline
\end{tabular}

NSAbs, Neuronal surface antibodies; CAs, Cerebellar ataxias; CSF, Cerebrospinal fluid.

This study reviewed 54 patients with IMCAs and identified 14 patients carrying different types of neural surface autoantibodies, including NMDAR-Ab, LGI-Ab, CASPR2-Ab, and AMPA2R$A b$. Anti-NSAbs-associated CAs mostly appeared in the first two weeks of the disease course of autoimmune encephalitis, and two patients (case 3 with CASPR2-Ab and case 13 with NMDAR-Ab) had isolated symptoms of CAs throughout the disease. Five patients with isolated CAs have been reported from publications previously $(7,22)$, including four with CASPR2$\mathrm{Ab}$ and one with NMDAR-Ab. Although the symptoms of isolated CAs were common in PCD, when patients suffered from isolated CAs, the diagnosis of autoimmune encephalitis should also be considered, especially anti-NMDAR or antiCASPR2 encephalitis. Anti-NSAbs-associated CAs showed less predominant truncal ataxia than PCDs. Mimicking Hashimoto's encephalopathy $(23,24)$, anti-NSAbs associated more frequently with additional extra-cerebellar symptoms, such as seizures and mental abnormalities, during the disease course.

Compared with other forms of IMCAs, a higher rate of pleocytosis and positive OB in CSF might have a predictive value for cerebellar symptoms in autoimmune encephalitis. In terms of imaging abnormalities on MRI, previous studies figured out that only $6 \%$ patients with anti-NMDAR encephalitis had cerebellar abnormalities and $13.3 \%$ patients suffered from progressive and irreversible cerebellar atrophy $(11,25)$. However, cerebellar atrophy in MRI was found in $16.7 \%$ patients with CASPR2-Ab (26) and those patients all benefited from immunotherapy (26). In this study, only one patient (case 3) with CASPR2-Ab had cerebellar atrophy. After immunotherapy, he was free from symptoms, and the existing cerebellar atrophy did not worsen in follow-up brain MRI.

All 14 patients received immunotherapy, and most encouragingly, two patients with isolated CAs (case 3 mentioned above and case 13) fully recovered and returned to work. Five patients presented with isolated CAs as reported previously, including 4 patients with CASPR2-Ab and 1 with NMDAR-Ab mentioned above $(7,22)$. The latter patient exhibited a partial improvement after immunotherapy (22), while the therapeutic response of the former 4 patients is unknown (7). The influencing factors of treatment effect were unclear, which might be related to the type of antibodies, the influence of accompanying symptoms and the severity of cerebellar inflammation. Further research is needed to explore the underlying mechanism of the pathophysiological function and the factors affecting the immunotherapy of anti-NSAbs associated CAs.
Among the many mechanistic studies of IMCAs, the association between ONA and PCDs has always been a research hotspot, but few studies have focused on the pathogenesis of anti-NSAbs associated CAs. In patients with PCD, previous studies have revealed a significant loss of Purkinje cells due to a cell-mediated cytotoxic immune response associated with activated CD8+ $\mathrm{T}$ cells and microglia in the cerebellum $(27,28)$. However, in patients with anti-NMDAR encephalitis, post-mortem studies demonstrated no profound loss of Purkinje cells in the cerebellum (11). The NMDAR is strongly expressed on the cerebellum and these receptors on granular cells (but not on Purkinje cells) were identified as a specific antigen of IgG antibodies, which might interfere with the excitatory pathway involving the NMDAR-mediated signaling, resulting in cerebellar dysfunction (29).

\section{CONCLUSION}

Cerebellar ataxias were rare and atypical in autoimmune encephalitis with neuronal surface antibodies. Patients with anti-NSAbs-associated CAs exhibited a higher positivity rate of $\mathrm{OB}$ in CSF. Most patients, especially those with isolated CAs, responded well to immunotherapy. Compared with other causes, anti-NSAbs-associated CAs led to more symptoms of encephalopathy and showed better therapeutic effects from immunotherapy. Considering the treatability of anti-NSAbsassociated CAs, it is valuable to perform serum and CSF NSAbs tests for patients with cerebellar ataxia.

\section{DATA AVAILABILITY STATEMENT}

The original contributions presented in the study are included in the article/supplementary material. Further inquiries can be directed to the corresponding author.

\section{ETHICS STATEMENT}

The studies involving human participants were reviewed and approved by The Ethics Committee of Xuanwu Hospital (No.2017YFC0907702). The patients/participants provided their written informed consent to participate in this study. 


\section{AUTHOR CONTRIBUTIONS}

YJ was the major contributors in writing the manuscript. YJ, ML, and DL conceptualized the study. YJ, MZ, and HW collected samples and data. ZH, LJ, JY, AL, and YW contributed to the diagnosis and treatment of patients. YW checked the final manuscript. All authors contributed to the article and approved the submitted version.

\section{FUNDING}

This work was supported by Beijing Postdoctoral Research Foundation [Grant No. 2021-ZZ-001], Beijing Municipal

\section{REFERENCES}

1. Dalmau J, Tüzün E, Wu HY, Masjuan J, Rossi JE, Voloschin A, et al. Paraneoplastic Anti-N-Methyl-D-Aspartate Receptor Encephalitis Associated With Ovarian Teratoma. Ann Neurol (2007) 61(1):25-36. doi: 10.1002/ana.21050

2. Lai M, Hughes EG, Peng X, Zhou L, Gleichman AJ, Shu H, et al. AMPA Receptor Antibodies in Limbic Encephalitis Alter Synaptic Receptor Location. Ann Neurol (2009) 65(4):424-34. doi: 10.1002/ana.21589

3. Irani SR, Alexander S, Waters P, Kleopa KA, Pettingill P, Zuliani L, et al. Antibodies to Kv1 Potassium Channel-Complex Proteins Leucine-Rich, Glioma Inactivated 1 Protein and Contactin-Associated Protein-2 in Limbic Encephalitis, Morvan's Syndrome and Acquired Neuromyotonia. Brain (2010) 133(9):2734-48. doi: 10.1093/brain/awq213

4. Lai M, Huijbers MG, Lancaster E, Graus F, Bataller L, Balice-Gordon R, et al. Investigation of LGI1 as the Antigen in Limbic Encephalitis Previously Attributed to Potassium Channels: A Case Series. Lancet Neurol (2010) 9 (8):776-85. doi: 10.1016/S1474-4422(10)70137-X

5. Lancaster E, Lai M, Peng X, Hughes E, Constantinescu R, Raizer J, et al. Antibodies to the GABA(B) Receptor in Limbic Encephalitis With Seizures: Case Series and Characterisation of the Antigen. Lancet Neurol (2010) 9 (1):67-76. doi: 10.1016/S1474-4422(09)70324-2

6. Titulaer MJ, Höftberger R, Iizuka T, Leypoldt F, McCracken L, Cellucci T, et al. Overlapping Demyelinating Syndromes and Anti-N-Methyl-DAspartate Receptor Encephalitis. Ann Neurol (2014) 75(3):411-28. doi: 10.1002/ana.24117

7. Becker EB, Zuliani L, Pettingill R, Lang B, Waters P, Dulneva A, et al. Contactin-Associated Protein-2 Antibodies in Non-Paraneoplastic Cerebellar Ataxia. J Neurol Neurosurg Psychiatry (2012) 83(4):437-40. doi: 10.1136/ jnnp-2011-301506

8. Jarius S, Steinmeyer F, Knobel A, Streitberger K, Hotter B, Horn S, et al. GABAB Receptor Antibodies in Paraneoplastic Cerebellar Ataxia. J Neuroimmunol (2013) 256(1):94-6. doi: 10.1016/j.jneuroim.2012.12.006

9. Mitoma H, Manto M, Hampe CS. Immune-Mediated Cerebellar Ataxias: Practical Guidelines and Therapeutic Challenges. Curr Neuropharmacol (2019) 17(1):33-58. doi: 10.2174/1570159X16666180917105033

10. Titulaer MJ, McCracken L, Gabilondo I, Armangué T, Glaser C, Iizuka T, et al. Treatment and Prognostic Factors for Long-Term Outcome in Patients With Anti-NMDA Receptor Encephalitis: An Observational Cohort Study. Lancet Neurol (2013) 12(2):157-65. doi: 10.1016/S1474-4422(12)70310-1

11. Iizuka T, Kaneko J, Tominaga N, Someko H, Nakamura M, Ishima D, et al. Association of Progressive Cerebellar Atrophy With Long-Term Outcome in Patients With Anti-N-Methyl-D-Aspartate Receptor Encephalitis. JAMA Neurol (2016) 73(6):706-13. doi: 10.1001/jamaneurol.2016.0232

12. Boyko M, Au KLK, Casault C, de Robles P, Pfeffer G. Systematic Review of the Clinical Spectrum of CASPR2 Antibody Syndrome. J Neurol (2020) 267 (4):1137-46. doi: 10.1007/s00415-019-09686-2

13. Graus F, Titulaer MJ, Balu R, Benseler S, Bien CG, Cellucci T, et al. A Clinical Approach to Diagnosis of Autoimmune Encephalitis. Lancet Neurol (2016) 15 (4):391-404. doi: 10.1016/S1474-4422(15)00401-9
Education Commission [Grant No. TJSH20161002502], National Natural Science Foundation of China [Grant No. 81771398], Beijing Key Clinical Speciality Excellence Project and National Support Provincial Major Disease Medical Services and Social Capability Enhancement Project.

\section{ACKNOWLEDGMENTS}

We would like to thank all patients participated in this study and the strong support of Xuanwu hospital.

14. Gu Y, Zhong M, He L, Li W, Huang Y, Liu J, et al. Epidemiology of AntibodyPositive Autoimmune Encephalitis in Southwest China: A Multicenter Study. Front Immunol (2019) 10:2611. doi: 10.3389/fimmu.2019.02611

15. Hadjivassiliou M. Immune-Mediated Acquired Ataxias. Handb Clin Neurol (2012) 103:189-99. doi: 10.1016/B978-0-444-51892-7.00011-5

16. Graus F, Delattre JY, Antoine JC, Dalmau J, Giometto B, Grisold W, et al. Recommended Diagnostic Criteria for Paraneoplastic Neurological Syndromes. J Neurol Neurosurg Psychiatry (2004) 75(8):1135-40. doi: 10.1136/jnnp.2003.034447

17. Jarius S, Wildemann B. 'Medusa-Head Ataxia': The Expanding Spectrum of Purkinje Cell Antibodies in Autoimmune Cerebellar Ataxia. Part 1: AntiMglur1, Anti-Homer-3, Anti-Sj/ITPR1 and Anti-CARP VIII. J Neuroinflamm (2015) 12:166. doi: 10.1186/s12974-015-0356-y

18. Jarius S, Wildemann B. 'Medusa Head Ataxia': The Expanding Spectrum of Purkinje Cell Antibodies in Autoimmune Cerebellar Ataxia. Part 3: Anti-Yo/ CDR2, Anti-Nb/AP3B2, PCA-2, Anti-Tr/DNER, Other Antibodies, Diagnostic Pitfalls, Summary and Outlook. J Neuroinflamm (2015) 12:168. doi: 10.1186/s12974-015-0358-9

19. Mitoma H, Adhikari K, Aeschlimann D, Chattopadhyay P, Hadjivassiliou M, Hampe CS, et al. Consensus Paper: Neuroimmune Mechanisms of Cerebellar Ataxias. Cerebellum (2016) 15(2):213-32. doi: 10.1007/s12311-015-0664-x

20. Mitoma H, Hadjivassiliou M, Honnorat J. Guidelines for Treatment of Immune-Mediated Cerebellar Ataxias. Cerebellum Ataxias (2015) 2:14. doi: 10.1186/s40673-015-0034-y

21. Jia Y, Li M, Wang H, Zhang M, Wang Y. The Peculiar Clinical Symptoms and Treatment of Limbic Encephalitis Associated With AMPA Receptor Antibody. Eur Neurol (2021) 84(3):206-11. doi: 10.1159/000515592

22. Poorthuis MHF, van Rooij JLM, Koch AH, Verdonkschot AEM, Leembruggen MM, Titulaer MJ. Cerebellar Ataxia as a Presenting Symptom in a Patient With Anti-NMDA Receptor Encephalitis. Neurol Neuroimmunol Neuroinflamm (2019) 6(4):e579. doi: 10.1212/NXI. 0000000000000579

23. Matsunaga A, Ikawa M, Fujii A, Nakamoto Y, Kuriyama M, Yoneda M. Hashimoto's Encephalopathy as a Treatable Adult-Onset Cerebellar Ataxia Mimicking Spinocerebellar Degeneration. Eur Neurol (2013) 69:14-20. doi: 10.1159/000342217

24. Nakagawa H, Yoneda M, Fujii A, Kinomoto K, Kuriyama M. Hashimoto's Encephalopathy Presenting With Progressive Cerebellar Ataxia. J Neurol Neurosurg Psychiatry (2007) 78:196-7. doi: 10.1136/jnnp.2006.093005

25. Dalmau J, Gleichman AJ, Hughes EG, Rossi JE, Peng X, Lai M, et al. AntiNMDA-Receptor Encephalitis: Case Series and Analysis of the Effects of Antibodies. Lancet Neurol (2008) 7(12):1091-8. doi: 10.1016/S1474-4422(08) 70224-2

26. Wang J, Qiu Z, Li D, Dong H, Hao J, Liu Z. Anti-Contactin-Associated Protein-Like 2 Antibody-Associated Cerebellar Ataxia: A Case Report and Literature Review. J Neuroimmunol (2021) 353:577515. doi: 10.1016/ j.jneuroim.2021.577515

27. Albert ML, Darnell JC, Bender A, Francisco LM, Bhardwaj N, Darnell RB. Tumor-Specific Killer Cells in Paraneoplastic Cerebellar Degeneration. Nat Med (1998) 4(11):1321-4. doi: 10.1038/3315 
28. Storstein A, Krossnes BK, Vedeler CA. Morphological and Immunohistochemical Characterization of Paraneoplastic Cerebellar Degeneration Associated With Yo Antibodies. Acta Neurol Scand (2009) 120(1):64-7. doi: 10.1111/j.1600-0404.2008.01138.x

29. Llansola M, Sanchez-Perez A, Cauli O, Felipo V. Modulation of NMDA Receptors in the Cerebellum. 1. Properties of the NMDA Receptor That Modulate Its Function. Cerebellum (2005) 4(3):154-61. doi: 10.1080/ 14734220510007996

Conflict of Interest: The authors declare that the research was conducted in the absence of any commercial or financial relationships that could be construed as a potential conflict of interest.
Publisher's Note: All claims expressed in this article are solely those of the authors and do not necessarily represent those of their affiliated organizations, or those of the publisher, the editors and the reviewers. Any product that may be evaluated in this article, or claim that may be made by its manufacturer, is not guaranteed or endorsed by the publisher.

Copyright (c) 2022 Jia, Li, Li, Zhang, Wang, Jiao, Huang, Ye, Liu and Wang. This is an open-access article distributed under the terms of the Creative Commons Attribution License (CC BY). The use, distribution or reproduction in other forums is permitted, provided the original author(s) and the copyright owner(s) are credited and that the original publication in this journal is cited, in accordance with accepted academic practice. No use, distribution or reproduction is permitted which does not comply with these terms. 